\title{
GHANA SCIENCE ASSOCIATION
}

$\mathrm{T}$ HE Ghana Science Association held for the first time a conference of all scientists in Ghana at Legon in the University College of Ghana during March 31-April 3. This coincided with the second anniversary of the Association, which was formed from the West African Science Association, after Nigeria had asked to form the Science Association of Nigeria about two years ago.

The conference was opened by the Hon. Kofi Baako, Minister of State for Presidential Matters in Parliament, who is also the Minister responsible to the President for National Research. He deputized for the President, Osagyefo Dr. Kwame Nkrumah. The Minister expressed the Osagyefo's great interest in science and its development in Ghana and appealed to the scientists to channel their efforts through peaceful uses of scientific discoveries. $\mathrm{He}$ also promised the help of the Government in the publication of a new scientific journal for the Association. The Minister's speech was followed by the presidential address of the Association, which was given by Mr. R. P. Baffuor, principal of the Kumasi College of Technology and the third and this year's president of the Association.

This conference appeared to have met with approval in Ghana, for although many international scientific conferences have been held in Ghana for some time past much publicity was given to this national conference by both the Press and the radio. The theme of the conference was "Science in the Development of Ghana", and no less than twenty-three papers were read in the three days in various branches of science such as physics, chemistry, botany, zoology, geology and geophysics, engineering, agriculture, medicine and soil science. The actual topics were not necessarily limited to Ghana. Most of the papers were of a general nature, and were presented for the understanding of all scientists irrespective of their speciality, but one afternoon was set aside for specialist papers, when the conference split into biological and physical sciences. Geology and soil science formed the biggest group of papers read.

The most popular paper was on traditional healing methods in Ghana, by Mr. W. S. Mensah-Dapaa, a Ghanaian science graduate who, for about two years, has been living at the shrine of a famous traditional healer at Larteh, a village about thirty-five miles from Accra. In his paper Mr. Mensah-Dapaa described in great detail the ceremony that surrounded the healing at this shrine and gave eye-witness accounts of the spectacular cures that had taken place there. He certainly aroused interest in this field, which has often been relegated to the limbo of non-scientific or quasi-spiritual practices. $\mathrm{He}_{e}$ appealed to the scientists to shed many of the false ideas about traditional healing, so that the best of this cult, which he claimed to be Africa's version of what prevails in varying forms all over the world, may be successfully studied and integrated into science and medicine. $\mathrm{He}_{e}$ also called for a department under the proposed medical school for studying the herbs and the methods of traditional healing.

Contributors were selected from all over Ghana, from the University College of Ghana, the College of Technology, research institutions like the West
African Cocoa Research Institute, the Government Scientific Civil Service, and private individuals.

One significant and encouraging aspect of the conference was that for the first time an appreciable number of young Ghanaian scientists read more than one-third of the papers.

On the first full-session day, April 1, nine papers were read. The Rev. Dr. J. R. Koster, the first scientist to record sounds from the Russian satellite in 1957, read a paper on "Radio Research in Ghana". He discussed the discovery of some unusual equatorial radio propagation problems in Ghana which affect television and radio broadcasting in Ghana and elsewhere. This was followed by an illuminating talk by Mr. O. W. Snow, adviser on agricultural science to the Government of Ghana, on "Agricultural Research in Relation to Development". With particular reference to the Gezira Cotton Scheme in the Sudan Republic, Mr. Snow showed how the proper utilization of the great potential of the results of agricultural research depended largely on other factors, such as systematic layout, availability of credit and some legalized form of marketing.

After this had been followed by the paper on traditional healing methods referred to above, Mr. A. Foggie, adviser on forestry matters, read his paper on "Conservation of Natural Resources in Ghana". He covered the problems of conservation of water, vegetation, soils and wild-life in Ghana. Another paper of great interest that day was one on "Radio Isotope Unit", by Dr. A. H. Ward, of the Physics Department of the University College, in which were described the various work being carried out in Ghana with radioisotopes and the potentialities of the Radio Isotope Unit installed at the University College. Other papers for the day included the following : "Some Aspects of Genetic Expressions in Agricultural Experimentation in Ghana", by Dr. Agble, deputy chief scientific officer ; "Grain Storage Problems in Ghana", by Mr. J. Forsyth, of the Faculty of Agriculture at the University College of Ghana, and finally, "The Role of Geology in the Development of Ghana", by Mr. L. A. K. Quashie, of the Geological Survey Department.

The following day was devoted to the specialist lectures. Under the chairmanship of Prof. W. J. McCallien the Physical Sciences group heard three papers. The first of these, which drew many listeners, was on "Geological and Archæological Evidence for the late Quaternary Climatic Sequence in West Africa", by Dr. O. Davies, a well-known archæologist who continues to make valuable contributions in this field in Ghana. This was followed by a paper by Dr. F. Torto, of the Department of Chemistry, on the structure of gums and mucilages in two Ghana plants, Fagara xanthoxyloides and Afraegle paniculata. The final paper of the day was on "A Seismic Investigation of the Depth of Bedrock under the Volta. River at Tefle", by Mr. F. W. Hales, senior geophysicist of the Geological Survey Department. $\mathrm{He}$ showed that the refraction method of analysis corroborated the depth-to-bedrock data obtained by drilling at the site of the proposed bridge across the Volta River at Tefle. 
The Biological Seiences group, under the chairmanship of Prof. F. W. Sansome, heard two papers on cocoa-one, "Comparable Growth Rates of Amazon and Amelonado Cocoa and Responses to Fertilizer", and the other, "Problems in the Assessment of Cocoa Varieties". The third paper was entitled "Liver Cirrhosis in Pigs in Ghana", in which the speaker, Mr. D. Zwart, introduced for discussion the problem of liver cirrhosis which attacked the local black pigs, and later also a few of the European ones, when kept under semi-intensive conditions.

The final full session day of the conference, April 3, opened with one of the popular topics, "Tuberculosis in Ghana", by the tuberculosis specialist in Ghana, Dr. A. Koch. Then followed a general paper by Prof. McCallien on "Seas and Oceans", treated with reference to geological problems in recent oceano. graphic studies.
Quite related to this topic was the next paper on "Outboard-Motor as a Prime Mover in the Development of Fisheries in Ghana", by Mr. E. A. Kwei, of the Government Fisheries Department. Among the other papers for the day were "The Correlation of Field, Laboratory and Analytical Studies of Engineering Structures", by Prof. Royston-Jones, of the Engineering Department, and "Classification of Black and Grey Clays of Ghana using the New U.S. System" presented by three workers led by Mr. H. B. Obeng, of the Scientific Services.

The closing address to round off the conference was given by Mr. H. O. Walker, former chief meteorologist, who made special mention of the many new Ghanaian scientists.

Arrangements are being made to publish the proceedings of the conference in the new scientific journal of the Association. J. YANNEY WILSON

\section{SATELLITES AND GEODESY}

$\mathrm{O}^{\mathrm{N}}$ N March 24, 1961, the Royal Astronomical Society held, at its rooms in Burlington House, a geophysical discussion on "Technique of Optical Observations". The chairman for the meeting was Dr. A. H. Cook (National Physical Laboratory), who opened by remarking that the exploration of the major feature of the Earth's gravitational potential by the conventional methods of geodesy was a topic which had often been discussed at meetings of the Society. This meeting, however, would be concerned rather with the elucidation of small-scale features and the use of observations of Earth satellite positions for this purpose.

The discussion was opened by short papers from four speakers, of whom the first was Brigadier G. Bomford. Geodesists had no difficulty, he said, in deriving the size, latitude and longitude and an appropriate geoid for a piece of land, using a variety of well-known astronomical measurements. The problem was to relate the resulting co-ordinate systems for two or more land masses which were separated by a wide sea. If there were no gaps of more than, say, 500 miles to be spanned, the land masses might be connected in latitude and longitude by radar, but this would not connect the two geoids.

However, the problem might be solved by a sufficient number of simultaneous observations of the position of a satellite from each of the land masses to be connected. It was possible that nonsimultaneous non-overlapping observations might be used, but this might also assume a knowledge of the geoid. Brigadier Bomford suggested that such observations would need, in order to be useful, to lead to measurements of position with an accuracy of 30 miles in a horizontal and 10 miles in a vertical direction. Connexions of this kind were required, for example, between Europe and America, across the Mediterranean and between many separated land masses in and around the Pacific.

Dr. R. d'E. Atkinson (Nautical Almanack Office) discussed the astrometric techniques which might be employed, of which there were several. One of the most convenient required the satellite to emit bright, short-duration flashes of light, which would then be photographed against the stars using a camera with an equatorial drive. If the stations were at known longitudes and latitudes, then the time of the flash was in general determined, but if longitude errors in the positions were to be taken out, a timing system with an accuracy of $1 \mathrm{msec}$. was required.

In this way, accuracies in the star positions of $0.05^{\prime \prime}$ could be obtained, but this was because the long exposure reduced errors due to 'seeing' (that is, irregular variations in tropospheric refraction). At low altitudes this effect might be very important and unfortunately connexions over long distances would usually involve large zenith distances. Thus, at a zenith distance of $70^{\circ}$ in a particular case, he had found that 'seeing' increased the angular diameter of the image from $2^{\prime \prime}$ to $4 \cdot 8^{\prime \prime}$, suggesting that the probable error of a single observation of a satellite might be $2^{\prime \prime}$, equivalent to perhaps \pm 60 miles in position. But with multiple observations there would be an improvement.

Alternatively, the conventional method of observing a satellite by reflected sunlight could be used, the observations being made by means of a camera having a shutter which would make timed breaks in the trail. This would be nearly as accurate. The principal problem in this case was to obtain east-west connexions over long distances, as each of the stations could not then be in the dark.

The third paper was read by Dr. A. P. Willmore (University College, London), who pointed out that a principal instrumental difficulty in making optical observations of satellite positions arose from the fact that, viewed from a point on the Earth's surface, a satellite moves with an angular velocity which is neither constant nor accurately predictable. The problem was then to obtain a sufficient exposure to record its position. The sensitivity of a detecting system might in general be limited in any of three ways: by the necessity for recording at least a few photon events in each image element, by statistical fluctuations in the background due to the night sky or by system noise (such as chemical fog, in the case of a photographic emulsion). When these were examined for any but a rather small optical system, it was found that at the high quantum yields characteristic of a photoelectric detector, the limitation always arose from the night sky background, while at the lower quantum yield of the photographic 